\title{
Detection of intracellular lgD using flow cytometry could be a novel and supplementary method to diagnose lgD multiple myeloma
}

\author{
Wei Wang, Chun-Xia Zhang, Zhen-Ling Li, Ming Gong and Yi-Gai Ma*
}

\begin{abstract}
Background: We examined whether detecting the heavy chain of cytoplasmic immunoglobulin D (IgD) by flow cytometry could be used as a supplemental method to diagnose lgD multiple myeloma (MM).

Methods: Bone marrow (BM) samples of thirty-five patients with MM were collected. Five of them were IgD MM, the rest of thirty were other subtypes of MM. Antibodies to four types of heavy chains of immunoglobulin (e.g., IgA, IgG, IgM, and IgD) were analyzed by flow cytometry in each patient's BM sample.

Results: The five IgD MM patients were all positive for cytoplasmic IgD. The percentage of IgD positive MM cells among nucleated cells varied from 0.4 to $12.9 \%$. Cytoplasmic lgG was positive in eight patients with IgG MM $(n=9)$; cytoplasmic IgA was positive in all patients with IgA MM $(n=10)$; cytoplasmic IgM was positive in one patient with $\operatorname{lgM} M M(n=1)$. No heavy chain was detected in light chain MM $(n=9)$ and non-secretory subtype $(n=1)$.

Conclusions: Detection of cytoplasmic lgD by flow cytometry is a convenient, sensitive and supplemental method to diagnose $\operatorname{lgD}$ MM.
\end{abstract}

Keywords: Multiple myeloma, IgD, Flow cytometry, Cytoplasmic IgD, Diagnosis

\section{Background}

Immunoglobulin D (IgD) multiple myeloma (MM) comprises 1 to $2 \%$ of all MM cases [1, 2]. It is characterized by occurrence in relatively young patients, osteolytic lesions, extramedullary involvement, amyloidosis, renal failure, and a poor prognosis [2-6]. Diagnosis of IgD $\mathrm{MM}$ is difficult because IgD can present minimal or even undetectable $\mathrm{M}$-protein spikes via serum protein electrophoresis (SPEP) [2, 7]. Thus, many cases present as hypogammaglobulinemia or have normal SPEP results. This could lead to misdiagnoses of patients in this subgroup $[8,9]$.

In this research, we describe a new method to detect cytoplasmic IgD in malignant plasma cells using multiple parameter flow cytometry as a supplementary method to diagnose IgD MM.

\footnotetext{
* Correspondence: dr_myg@163.com

Hematology Department, China-Japan Friendship Hospital, Ying-Hua-Yuan East Street, No. 2, Beijing 100029, China
}

\section{Methods \\ Patients}

The study was approved by the Ethical Committee of the China-Japan Friendship Hospital (Reference Number: 81300450). It was conducted in accordance with the ethical standards described in the 1964 Declaration of Helsinki and its later amendments or comparable ethical standards. Written informed consents for participation in the study were obtained from participants. Bone marrow (BM) samples from ten patients with newly diagnosed $M M$ and twenty-five MM patients after chemotherapy were collected from February 2016 to November 2017. The median age was 66 years (range, 45-81 years). All patients were diagnosed based on the International Myeloma Working Group (IMWG) diagnostic criteria [10].

(C) The Author(s). 2018 Open Access This article is distributed under the terms of the Creative Commons Attribution 4.0 International License (http://creativecommons.org/licenses/by/4.0/), which permits unrestricted use, distribution, and reproduction in any medium, provided you give appropriate credit to the original author(s) and the source, provide a link to the Creative Commons license, and indicate if changes were made. The Creative Commons Public Domain Dedication waiver (http://creativecommons.org/publicdomain/zero/1.0/) applies to the data made available in this article, unless otherwise stated. 


\section{Monoclonal immunoglobulin detection}

Monoclonal immunoglobulins were detected by SPEP, urine protein electrophoresis (UPEP), serum and urine immunofixation electrophoresis (IFE), and serum and urine-free light-chain (FLC) assays $[11,12]$. In this study, we refer to these methods as traditional methods, and use them as the gold standard criteria to evaluate the diagnostic efficiency of flow cytometry as for detecting the expression of cytoplasmic immunoglobulin heavy chain.

\section{Flow cytometry analysis}

For flow cytometry analysis, BM samples from ten patients before chemotherapy and samples from twenty-five patients after chemotherapy were evaluated.

The following monoclonal antibodies (mAbs) were purchased from DAKO: anti-IgA FITC (F0188), anti-IgG FITC (F0185), anti-IgM PE (R5111), anti-Kappa PE (R0436), and anti-Lambda FITC (F0435). Anti-IgD PE (348204) was purchased from Biolegend. The following

Table 1 Clinical information of patients with IgD MM before chemotherapy

\begin{tabular}{|c|c|c|c|c|c|}
\hline $\begin{array}{l}\text { Patient No } \\
\text { Items }\end{array}$ & 1 & 2 & 3 & 4 & 5 \\
\hline$\overline{\text { Age }}$ & 75 & 68 & 45 & 55 & 62 \\
\hline Sex & Male & Male & Male & Female & Male \\
\hline Durie-Salmon staging system & IIIA & $\| \mathrm{B}$ & IIIA & $\| \mathrm{A}$ & $\| \mathrm{B}$ \\
\hline International staging system & III & III & $\|$ & III & III \\
\hline RISS stage & III & $\|$ & $\|$ & $\|$ & $\|$ \\
\hline Extramedullary involvement & The liver is involved & None & None & None & Pulmonary involvement \\
\hline Multiple lytic bone lesions (X-ray) & None & None & Positive & Positive & Positive \\
\hline BM sample of Congo red Staining & Negative & Negative & Negative & Negative & Negative \\
\hline BM biopsy Involvement of MM cells & Diffuse & Diffuse & Focal & Diffuse & Diffuse \\
\hline $\begin{array}{l}\text { Percentage of plasma cells in BM } \\
\text { (Morphology) }\end{array}$ & $73.5 \%$ & $60.5 \%$ & $46.5 \%$ & $72.5 \%$ & $35.5 \%$ \\
\hline $\begin{array}{l}\text { Percentage of plasma cells in BM } \\
\text { (Flow cytometry) }\end{array}$ & $12.9 \%^{\mathrm{a}}$ & $8.2 \%^{\mathrm{a}}$ & $4.1 \%^{\mathrm{a}}$ & $3.3 \%^{\mathrm{a}}$ & $0.4 \%$ \\
\hline Chromosomal study & $\begin{array}{l}\text { Complex chromosomal } \\
\text { Abnormalities }\end{array}$ & $45, X,-Y$ & Normal & $46, X X, \operatorname{inv}(9)(p 12 q 13)$ & $\begin{array}{l}\text { Complex chromosomal } \\
\text { abnormalities }\end{array}$ \\
\hline $\mathrm{FISH}$ & $t(11 ; 14)$ & Normal & Normal & Normal & $t(11 ; 14)$ \\
\hline \multicolumn{6}{|l|}{ CBC } \\
\hline WBC $\left(\times 10^{9} / L\right)$ & 3.57 & 6.54 & 3.86 & 3.52 & 10.63 \\
\hline $\mathrm{HGB}(\mathrm{g} / \mathrm{dL})$ & 2.7 & 7.0 & 8.3 & 11.9 & 8.3 \\
\hline $\operatorname{PLT}\left(\times 10^{9} / \mathrm{L}\right)$ & 59 & 138 & 101 & 213 & 242 \\
\hline LDH (U/L) (100 250) & 291 & 231 & 177 & 180 & 217 \\
\hline Serum calcium & Low & Low & Normal & Normal & Normal \\
\hline Albumin (g/dL) & 38 & 30 & 43 & 42 & 40 \\
\hline Serum $\beta 2$ micoglobulin (mg/L) & 11.39 & 27.63 & 4.06 & 7.40 & 10.14 \\
\hline Serum creatinine $\mathrm{mg} / \mathrm{dL}$ & 1.4 & 8.2 & 0.9 & 1.1 & 2.0 \\
\hline \multicolumn{6}{|l|}{ Serum $\lg (\mathrm{mg} / \mathrm{dL})$} \\
\hline $\lg \mathrm{D}$ & 364 & Trace $^{\mathrm{b}}$ & 653 & 1063 & 394 \\
\hline $\lg A$ & 16.3 & 35.7 & 15.5 & 4.87 & 21.4 \\
\hline $\lg G$ & 523 & 545 & 427 & 1110 & 618 \\
\hline $\lg M$ & 9.4 & 10.4 & 5.1 & 72.8 & 22 \\
\hline Serum light chain type & Lambda & Lambda & Lambda & Lambda & Lambda \\
\hline Urine M protein (g/day) & 5.80 & 0.31 & 6.25 & 3.95 & 0 \\
\hline Overall survival (month) & 6 & 4 & 31 & 13 & 39 \\
\hline Living state & Dead & Dead & Alive & Dead & Alive \\
\hline
\end{tabular}

${ }^{\mathrm{a}}$ Flow cytometry analysis was performed to these patients after chemotherapy

${ }^{\mathrm{b}}$ The IgD was too low to detect. The serum IgD of this patient was detected after four cycles of chemotherapy

$B M$ bone marrow, $M M$ multiple myeloma, $l g$ immunoglobulin, $C B C$ complete blood count, $M$ protein, monoclonal protein 


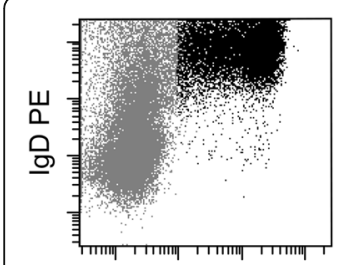

CD138 APC

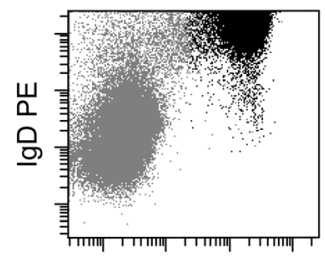

CD138 APC

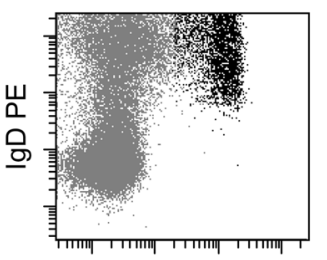

CD138 APC

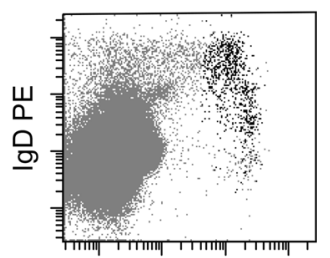

CD138 APC

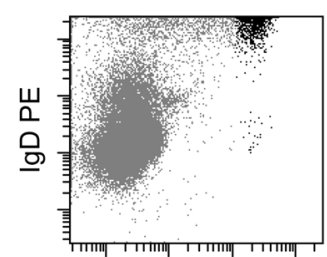

CD138 APC

Fig. 1 Flow cytometry results for five patients with IgD MM. Bone marrow samples from five patients with IgD MM were analyzed by flow cytometry. Expression of cytoplasmic lgD in MM cells was positive in each patient

mAbs were purchased from Becton Dickinson (BD): anti-CD19 V450 (560353), anti-CD20 APC-H7 (560734), anti-CD38 PC7 (560677), anti-CD45 V500 (560777), and anti-CD138 APC (566050). The following mAb panels were used in the study: CD19 V450/CD45 V500/ cytoplasm IgG FITC/ cytoplasm IgM PE/CD38 PC7/CD138 APC/CD20 APC-H7; CD19 V450/CD45 V500/ cytoplasm IgA FITC/cytoplasm IgD PE/CD38 PC7/CD138 APC/ CD20 APC-H7; CD19 V450/CD45 V500/cytoplasm Lambda FITC/cytoplasm Kappa PE/CD38 PC7/CD138 APC/CD20 APC-H7. An IntraStain kit (K2311, DAKO) was used for intracellular staining. BD FACS Lysing Solution $(349,202, \mathrm{BD})$ was used to lyse red blood cells.

BM samples were collected in heparin anticoagulant tubes; then, $5 \times 10^{5}$ white blood cells per tube were stained and analyzed within $6 \mathrm{~h}$ after procurement. All samples were analyzed using FACS CantoII and Davi software (both from BD).

The gate strategy was as follows: first, we used the FCS/SSC to remove dead cells; second, we used FSC-A/ FSC-H to remove cells that were clumped together; third, we delineated plasma cells on the CD38/CD138 dot plot; fourth, we used CD45 and CD19 to identify malignant plasma cells in each tube; and finally, the intracellular expression of light chains or heavy chains of immunoglobulin was detected in the malignant plasma cellular population. The phenotypes of malignant plasma cells include CD38 positive/dim/negative, CD138 positive, CD45 ${ }^{\text {dim/negative }}, \mathrm{CD} 19^{\text {negative }}[13]$.

\section{Statistical analysis}

A Chi-square test was used to calculate the diagnostic coherence between flow cytometry and traditional methods (e.g., SPEP, UPEP, serum and urine IFE, serum and urine FLC assay). The statistical test was two-sided, with significance defined as $p<0.05$. Analyses were calculated using SPSS version 17.0 (SPSS Inc., Chicago).

\section{Results}

First, we chose four patients with IgD MM after receiving chemotherapy and then detected the expression of four types of cytoplasmic immunoglobulin heavy chains in residual MM cells from their BM samples. Then, we used the same method to analyze ten BM samples from newly diagnosed MM patients and twenty-one samples from MM patients after chemotherapy. Five IgD MM patients diagnosed by traditional methods were all positive for cytoplasmic IgD. The clinical information of the five patients is listed in Table 1. The percentage of MM cells among nucleated cells varied from 0.4 to $12.9 \%$. The flow cytometry results of the five patients are shown in Fig. 1.

Diagnostic results obtained using flow cytometry and traditional methods are listed in Table 2. Among 9 IgG MM patients, the cytoplasmic IgG of 8 patients was detected by flow cytometry. The cytoplasmic IgM was detected in 1 patient with IgM MM, and the cytoplasmic IgA was detected in 10 patients with IgA MM, while no cytoplasmic heavy chain was detected in 9 patients with light chain $\mathrm{MM}$ and 1 patient with non-secretory MM. Expression of other heavy chains by flow cytometry in a particular type of heavy chain myeloma were negative. The flow cytometry results of cytoplasmic heavy chain of three patients with IgA, IgG, and IgM MM respectively are shown in Fig. 2 . And the flow cytometry results of a patient with light-chain MM are shown in Fig. 3.

\section{Discussion}

IgD MM is a rare type of MM due to its low prevalence and the low sensitivity of its diagnostic methods.

Table 2 Diagnostic result of MM patients by using flow cytometry and traditional methods

\begin{tabular}{llll}
\hline Subtype & Flow cytometry $(\mathrm{n})$ & Traditional methods $^{\mathrm{a}}(\mathrm{n})$ & $P$ \\
\hline $\lg \mathrm{P}$ & 5 & 5 & $>0.05$ \\
$\lg \mathrm{l}$ & 8 & 9 & $>0.05$ \\
$\lg \mathrm{M}$ & 1 & 1 & $>0.05$ \\
$\lg A$ & 10 & 10 & $>0.05$ \\
Light chain & 9 & 9 & $>0.05$ \\
Non-secretory & 1 & 1 & $>0.05$ \\
\hline
\end{tabular}

$M M$ multiple myeloma, $\lg D$ immunoglobulin $\mathrm{D}, \lg G$ immunoglobulin $\mathrm{G}, \lg M$ immunoglobulin $\mathrm{M}, \lg \mathrm{A}$ immunoglobulin $\mathrm{A}$

${ }^{a}$ The monoclonal immunoglobulin was detected by serum protein electrophoresis, urine protein electrophoresis; serum and urine immunofixation electrophoresis (IFE); serum and urine free light chain (FLC) assay. In this article, we named these methods as traditional methods 

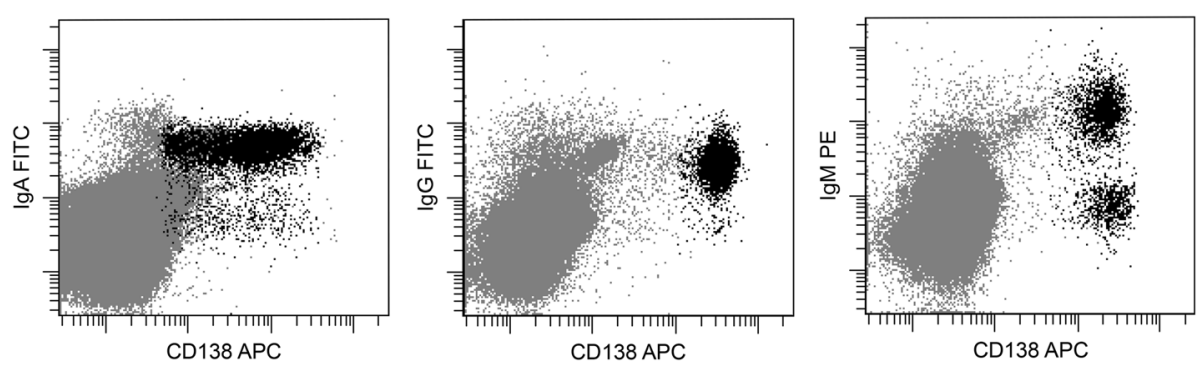

Fig. 2 Flow cytometry results of MM patients with other heavy chain subtypes. Bone marrow samples of patients with $\lg A$, IgG, or $\lg M$ MM were analyzed by flow cytometry. We chose one typical example of each subtype to display. The positive expression of cytoplasmic lgA, lgG, and lgM is shown from left to right

According to other reports, lower M protein level is not uncommon in IgD MM [3, 14]. The serum M protein of higher than $2 \mathrm{~g} / \mathrm{dl}$ was detected in only $14 \%$ of IgD MM patients [2], and the urine light chain on electrophoresis of higher than $4 \mathrm{~g} / \mathrm{d}$ and $1 \mathrm{~g} / \mathrm{d}$ was observed in $28 \%$ [2] and $61 \%$ [4] of IgD MM patients, respectively. A previous study showed a high sensitivity for detecting IgD in IgD MM patients using two-dimensional gel electrophoresis. However, the authors considered this technique time-consuming, difficult to perform, and expensive. Therefore, they would not recommend it as the first-line procedure to routinely diagnose IgD MM [15].

To evaluate whether detecting cytoplasmic IgD using flow cytometry could be a reliable supplemental method to diagnose IgD MM, we chose four patients with IgD MM after receiving chemotherapy and successfully detected positive expression of cytoplasmic IgD in residual MM cells from their BM samples (No. 1 4). We also evaluated a patient newly diagnosed with IgD MM (No. 5 ) and detected the IgD level using both flow cytometry and the traditional methods.

BM samples of four IgD MM patients (No. 1 4) were evaluated by flow cytometry after chemotherapy, while the percentages of malignant plasma cells in BM from the same patients were evaluated by morphology before treatment. Only one BM sample (No. 5) was concurrently analyzed by morphology and flow cytometry before chemotherapy. In the fifth patient, the BM was fully packed with MM cells. During BM collection, difficulty was experienced when aspirating a BM sample, and the sample was tremendously diluted by peripheral blood. This might be the reason that $35.5 \%$ of MM cells were detected by morphology, but only $0.4 \%$ of $\mathrm{MM}$ cells were detected by flow cytometry.

As shown in the results, the minimal proportion of IgD-positive MM cells detected by flow cytometry was $0.4 \%$. This finding demonstrated that flow cytometry is a sensitive method to detect very low amounts of IgD MM cells.

Since detecting cytoplasmic IgD in patients with IgD MM has been worked so well, we want to answer the following questions: Can cytoplasmic IgD only be detected in IgD MM? In MM patients with IgA, IgG, or IgM subtype, can the corresponding cytoplasmic Ig heavy chain be detected in MM cells? How the expression levels of the four heavy chains in MM patients with light chain or non-secretory subtype? So we estimated the presence of the four immunoglobulin heavy chains in other MM subtypes. The diagnostic consistency between flow cytometry and traditional methods was $96.67 \%$ (29/30 patients). Only one IgG MM patient had a negative cytoplasmic IgG result based on flow cytometry analysis.

As for the technique itself, flow cytometry is easy to perform and suitable for routine clinical use.

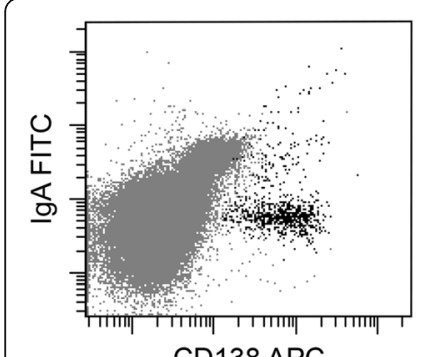

CD138 APC

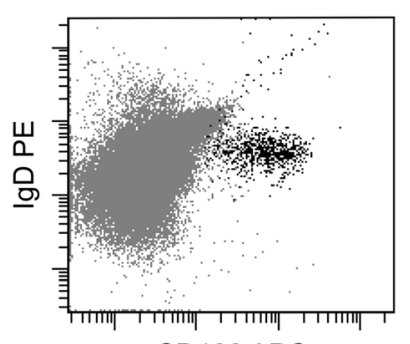

CD138 APC

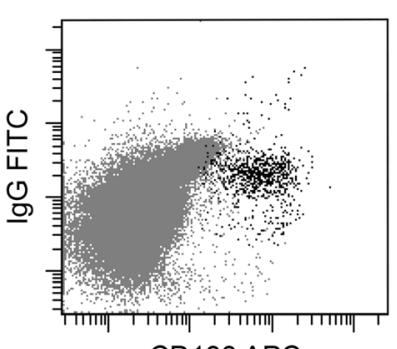

CD138 APC

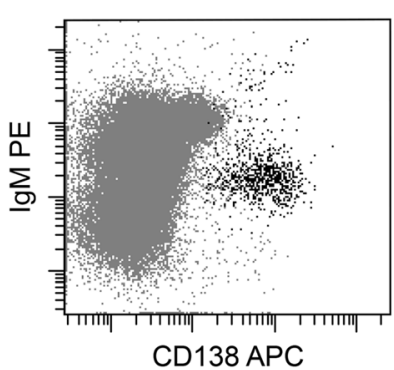

CD138 APC

Fig. 3 Flow cytometry results of MM patients with light-chain subtypes. Bone marrow samples of nine light-chain MM patients were analyzed by flow cytometry. The flow cytometry results of a representative patient are shown. The negative expression of cytoplasmic IgA, IgD, IgG, and IgM is shown from left to right 


\section{Conclusions}

Detection of cytoplasmic IgD using flow cytometry could be a convenient, sensitive, and supplemental method to diagnose IgD MM. Analysis of additional samples is needed to certify the use of this technique in clinical applications. This technique might be recommended as a routine procedure in the future.

\section{Abbreviations}

BM: Bone marrow; CBC: Complete blood count; FLC: Free light chain; IFE: Immunofixation electrophoresis; IgD: Immunoglobulin D; IMWG: International Myeloma Working Group; M protein: Monoclonal protein; mAbs: Monoclonal antibodies; MM: Multiple myeloma; SPEP: Serum protein electrophoresis; UPEP: Urine protein electrophoresis

\section{Acknowledgements}

All authors would like to thank Jing-Kai Lin, Wen-Tao Zhang, Yan Li, Bo-Yan Liu and Feng-Ming Kan for their help.

\section{Funding}

This work was supported by the National Natural Science Foundation of China (Grant No. 81300450). The funding body had no role in the design of the study and collection, analysis, and interpretation of data and in writing the manuscript.

\section{Availability of data and materials}

All data are presented in the manuscript.

\section{Authors' contributions}

WW planned the entire research study, performed the flow cytometry experiments, and wrote the manuscript. CXZ collected patient information, and finished the statistic analysis. ZLL collected patient samples, and revised the manuscript. MG collected patient samples, analyzed, and interpreted the results. YGM supervised the entire research plan and revised the manuscript. All authors read and approved the final manuscript.

\section{Ethics approval and consent to participate}

The study has been approved by the Ethical Committee of the China-Japan Friendship Hospital (Reference Number: 81300450) and has been performed in accordance with the ethical standards as described in the 1964 Declaration of Helsinki and its later amendments or comparable ethical standards. All patients were provided with informed written consent regarding the data collection and publication.

\section{Consent for publication}

We obtained written permission from all patients in the study to publish the manuscript reporting individual patient data.

\section{Competing interests}

The authors declare that they have no competing interests.

\section{Publisher's Note}

Springer Nature remains neutral with regard to jurisdictional claims in published maps and institutional affiliations.

Received: 26 February 2018 Accepted: 30 May 2018

Published online: 11 June 2018

\section{References}

1. Kim MK, Suh C, Lee DH, Min CK, Kim SJ, Kim K, et al. Immunoglobulin D multiple myeloma: response to therapy, survival, and prognostic factors in 75 patients. Ann Oncol. 2011;22:411-6.

2. Blade J, Lust JA, Kyle RA. Immunoglobulin D multiple myeloma: presenting features, response to therapy, and survival in a series of 53 cases. J Clin Oncol. 1994;12:2398-404

3. Morris C, Drake M, Apperley J, lacobelli S, van Biezen A, Bjorkstrand B, et al. Efficacy and outcome of autologous transplantation in rare myelomas. Haematologica. 2010;95:2126-33.
4. Reece DE, Vesole DH, Shrestha S, Zhang MJ, Perez WS, Dispenzieri A, et al. Outcome of patients with IgD and IgM multiple myeloma undergoing autologous hematopoietic stem cell transplantation: a retrospective CIBMTR study. Clin Lymphoma Myeloma Leuk. 2010;10:458-63.

5. Bataille R, Harousseau JL. Multiple myeloma. N Engl J Med. 1997;336:1657-64.

6. Shimamoto Y, Anami Y. Yamaguchi M. A new risk grouping for lgD myeloma based on analysis of 165 Japanese patients. Eur J Haematol. 1991; 47:262-7.

7. Shimamoto Y. IgD myeloma: clinical characteristics and a new staging system based on analysis of Japanese patients. Cancer Detect Prev. 1995;19: 426-35.

8. Stulik J, Tichy M, Kovarova H. Two-dimensional gel electrophoresis of four serum samples from patients with IgD myeloma. Clin Chim Acta. 1993;218: 149-58.

9. Arpin C, de Bouteiller O, Razanajaona D, Fugier-Vivier I, Briere F, Banchereau $J$, et al. The normal counterpart of IgD myeloma cells in germinal center displays extensively mutated IgVH gene, Cmu-Cdelta switch. and lambda light chain expression J Exp Med. 1998;187:1169-78.

10. International Myeloma Working G. Criteria for the classification of monoclonal gammopathies, multiple myeloma and related disorders: a report of the international myeloma working group. Br J Haematol. 2003;121:749-57.

11. Dispenzieri A, Kyle R, Merlini G, Miguel JS, Ludwig H, Hajek R, et al. International myeloma working group guidelines for serum-free light chain analysis in multiple myeloma and related disorders. Leukemia. 2009;23:215-24.

12. Rajkumar SV, Dimopoulos MA, Palumbo A, Blade J, Merlini G, Mateos MV, et al. International myeloma working group updated criteria for the diagnosis of multiple myeloma. Lancet Oncol. 2014;15:e538-48.

13. Flores-Montero J, de Tute R, Paiva B, Perez JJ, Bottcher S, Wind H, et al. Immunophenotype of normal vs. myeloma plasma cells: toward antibody panel specifications for MRD detection in multiple myeloma. Cytometry $B$ Clin Cytom. 2016;90:61-72.

14. Pandey S, Kyle R. Unusual myeloma: a review of $\operatorname{lgD}$ and IgE variants. Oncology (Williston Park). 2013;27:5.

15. Spertini F, Tissot JD, Dufour N, Francillon C, Frei PC. Role of two-dimensional electrophoretic analysis in the diagnosis and characterization of lgD monoclonal gammopathy. Allergy. 1995;50:664-70.

\section{Ready to submit your research? Choose BMC and benefit from:}

- fast, convenient online submission

- thorough peer review by experienced researchers in your field

- rapid publication on acceptance

- support for research data, including large and complex data types

- gold Open Access which fosters wider collaboration and increased citations

- maximum visibility for your research: over $100 \mathrm{M}$ website views per year

At BMC, research is always in progress.

Learn more biomedcentral.com/submissions 